\title{
La calidad de vida en el trabajo: la experiencia de los profesionales de la salud en una Unidad Básica de Salud en Minas Gerais - Brasil
}

\section{Quality of life at work: the experience of health professionals in a Basic Health Unit in Minas Gerais - Brazil}

\section{Qualidade de vida no trabalho: vivência de profissionais de saúde de uma Unidade Básica de Saúde de Minas Gerais - Brasil}

Ernandes Gonçalves Diass ${ }^{1}$, Alexandre Rodrigues dos Santos², Eleiane Lucinária Santos Souza ${ }^{3}$, Marlúcia Mendes Ladeia Araújo ${ }^{4}$, Janine Cinara Silveira Alves ${ }^{5}$

${ }^{1}$ Enfermeiro Mestrando do Programa de Tecnologia e Inovação em Enfermagem na USP-Ribeirão Preto. Especialista em Docência na Saúde e Enfermagem do Trabalho. Docente na Faculdade Presidente Antônio Carlos de Porteirinha e Faculdade Verde Norte (FAVENORTE). Porteirinha, Minas Gerais, Brasil.

2,3,4 Bacharel em Enfermagem. Faculdade Presidente Antônio Carlos de Porteirinha. Porteirinha-MG.

${ }^{5}$ Mestre em Ensino de Biologia. Docente na Faculdade Presidente Antônio Carlos de Porteirinha. Porteirinha-MG.

Cómo citar este artículo en edición digital: Dias, E.G., Santos, A.R., Souza, E.L.S., Araujo, M.M.L., \& Alves, J.C.S. (2017). La calidad de vida en el trabajo: la experiencia de los profesionales de la salud en una Unidad Básica de Salud en Minas Gerais -

Brasil. Cultura de los Cuidados (Edición digital), 21(48). Recuperado de < http://dx.doi.org/10.14198/cuid.2017.48.18>

\section{Correspondência:}

Ernandes Gonçalves Dias. Faculdade Presidente Antônio Carlos de Porteirinha e Faculdade Verde Norte (FAVENORTE).

Porteirinha, Minas Gerais, Brasil.

Correo electrónico: nandesenf@usp.br

Recibido: 19/12/2016; Aceptado: 07/03/2017

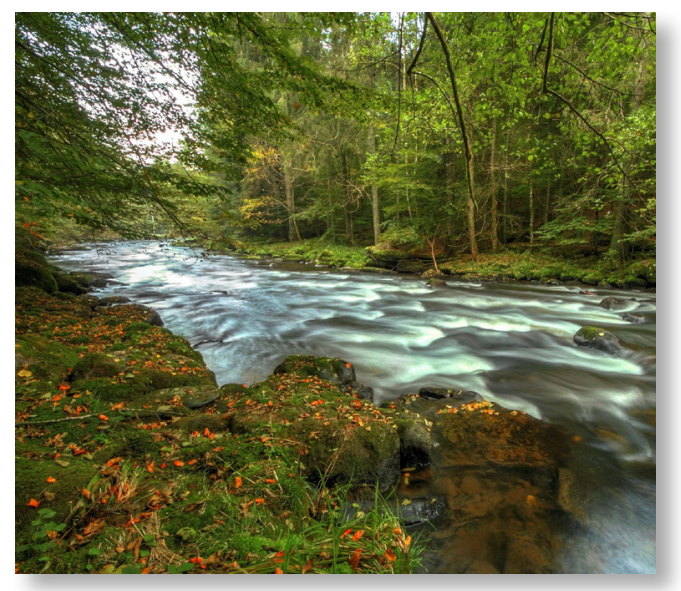

ABSTRACT

Objective: verify the perception of suffering in the work of health professionals in the Basic Health Unit Delson Pinheiro de Aguiar in Serranópolis Minas.

Methods: This is an exploratory cross-sectional study of qualitative approach. Data were collected from March to April 2015, through a semi-structured interview applied to 12 health professionals.

Results: It was observed that most professionals find pleasure in work accomplished due helping others, contribute to improving the population's quality of life, bring information and relief of pain and pleasure for what they do. The situations that cause dissatisfaction or suffering at work are lack of recognition for the efforts made in implementing the work, indifference in interpersonal relationships between professionals and lack of friendship.

Conclusion: In this way it is up for service managers intervene in the work process yielding to professionals best working conditions.

Keywords: Quality of life, health personnel, job satisfaction, health centers. 


\section{RESUMEN}

Objectivo: verificar la percepción del sufrimiento en el trabajo de los profesionales de la salud Unidad Básica de Salud Delson Pinheiro de Aguiar en Serranópolis Minas.

Método: Se trata de un estudio transversal exploratorio de abordaje cualitativo. Los datos fueron recolectados de marzo a abril 2015, a través de una entrevista semiestructurada aplicada a 12 profesionales de la salud.

Resultados: Se observó que la mayoría de los profesionales encuentran placer en el trabajo, ya ayudar a los demás, contribuyen a mejorar la calidad de vida de la población, llevar la información y el alivio del dolor y el placer por lo que hacen. Las situaciones que causan sufrimiento es la falta de reconocimiento por los esfuerzos realizados en la ejecución de la obra, la indiferencia en las relaciones interpersonales entre los profesionales y la falta de colegialidad.

Conclusión: Es necesario que los profesionales de la salud tienen el reconocimiento y apreciación en cuanto a su trabajo, por lo que el sufrimiento de las experiencias se puede mejorar.

Palabras clave: Calidad de vida, personal de salud, satisfacción en el trabajo, centros de salud.

\section{RESUMO}

Objetivo: verificar a percepção de sofrimento no trabalho de profissionais de saúde da Unidade Básica de Saúde Delson Pinheiro de Aguiar em Serranópolis de Minas.

Método: Trata-se de um estudo exploratório e transversal de abordagem qualitativa. Os dados foram coletados no período de março a abril de 2015 através de uma entrevista semiestruturada aplicada a 12 profissionais de saúde.

Resultados: Observou-se que a maioria dos profissionais encontra prazer no trabalho realizado devido ajudar o próximo, contribuir para melhoria na qualidade de vida da população, levar informação e alívio das dores, bem como sentir prazer pelo que fazem. As situações que causam sofrimento são a falta de reconhecimento em relação aos esforços realizados na execução do trabalho, indiferença no relacionamento interpessoal entre os profissionais e falta de coleguismo.

Conclusão: É preciso que os profissionais de saúde tenham reconhecimento e valorização quanto a seu trabalho, para que as vivências de sofrimento possam ser amenizadas.

Palavras-Chave: Qualidade de vida, pessoal de saúde, satisfação no emprego, centros de saúde.

\section{INTRODUÇÃO}

A Qualidade de Vida no Trabalho (QVT) pode ser definida pelos aspectos físicos, ambientais e psicológicos do local de trabalho, tais como motivação, satisfação, qualidade de trabalho, modo de liderança, entre outros (Roble, 2012).

É evidente que QVT sofre influências de diversas variáveis, como reações interpessoais no ambiente de trabalho, satisfação com a remuneração, reconhecimento e valorização da atividade exercida. Da mesma forma, fatores externos ao ambiente de trabalho como vida pessoal, saúde, lazer e estado emocional também estão relacionados com a QVT (Ferro, 2012).

O trabalho atua desfavoravelmente ao homem quando é fragmentado e sem sentido, repetitivo, com normas e rotinas impostas sem dar ao colaborador oportunidade de decidir, criar e ser autônomo na execução de suas tarefas, além de, às vezes, causar conflito com a vida social e familiar (Ferreira, Todecast e Weinzierl, 2012). 
A interação adequada entre o sistema e o indivíduo cria um clima organizacional que atende as necessidades pessoais e as de caráter institucionais. Isto origina efeitos positivos expressados em motivação e satisfação individual que, por si, determinam uma melhor realização das tarefas e alcance dos objetivos organizacionais (Paula et al., 2011).

No desenvolvimento do trabalho em saúde e na procura pela implementação dos objetivos e metas, a equipe de saúde deve ter consciência da existência de desavenças, sejam elas internas ou externas à equipe. $\mathrm{O}$ processo de trabalho em saúde está formado por ação ou estado social, psíquico ou biológico, cuja alteração pode ter impacto positivo ou negativo sobre a saúde de indivíduos, grupos de pessoas ou comunidades (Faria, 2009).

O desgaste emocional nos trabalhadores de saúde diz mais sobre as condições de trabalho dos colaboradores do que sobre eles mesmos. Algumas das maiores fontes do desgaste podem ser: excesso de trabalho, falta de controle, falta de recompensa, falta de união, falta de equidade e conflito de valores. $\mathrm{O}$ desgaste afeta tanto o indivíduo e seus familiares quanto às empresas. Uma das soluções para este problema poderia ser a criação, pela empresa, de ações preventivas, como programas de QVT (Alves, 2011).

As organizações, para obterem de seus colaboradores uma melhor produtividade e execução de suas funções, precisam investir em seus funcionários, proporcionando aos mesmos, maior satisfação e motivação para a realização de suas atividades de trabalho (Andrade, 2012).

Pensando dessa forma surgiu o interesse em abordar o tema QVT dos profissionais da saúde da cidade de Serranópolis de Minas. É difícil ofecer cuidados de saúde qualificados, sem que os profissionais que atuam na saúde tenham uma boa QVT. Sabe-se que em uma instituição de saúde se encontra variados tipos de doenças e situações que geram abalo emocional nos trabalhadores e que muitas vezes acabam comprometendo a QVT dos mesmos.

Diante do exposto torna-se relevante, estudar a QVT dos profissionais da saúde de Serranópolis de Minas, haja vista que é de grande importância conhecer como é a vida dos profissionais. Neste contexto, a presente investigação tem como objetivo conhecer a percepção de satisfação e sofrimento no trabalho de profissionais de saúde da Unidade Básica de Saúde Delson Pinheiro de Aguiar em Serranópolis de Minas.

\section{MATERIAL E MÉTODOS}

Trata-se de um estudo exploratório e transversal, desenvolvido mediante uma abordagem qualitativa, realizado na Unidade Básica de Saúde Delson Pinheiro de Aguiar na cidade de Serranópolis de Minas em Minas Gerais.

Foram pesquisados 12 profissionais de saúde, total de trabalhadores da Unidade, sem restrição de idade, gênero, raça, religião ou classe social. $\mathrm{O}$ método de seleção da amostra foi convencional e intencional de acordo com a disponibilidade e interesse dos profissionais no momento da coleta de dados.

Dessa forma, foram inclusos todos os profissionais da saúde, funcionários da Unidade em estudo, que estavam trabalhando no primeiro semestre do ano de 2015 e que assinaram o Termo de Consentimento Livre e Esclarecido, conforme determina a Resolução 466/2012, que trata das pesquisas que envolvem seres humanos.

Foi utilizado como instrumento de coleta de dados uma entrevista com roteiro semiestruturado com as seguintes questões norteadoras: "Seu trabalho lhe causa prazer? Quais situações em seu trabalho lhe causam prazer/satisfação?", 
"Seu trabalho lhe causa algum sofrimento? Que situações em seu trabalho lhe causam sofrimento/insatisfação?", "Possui algum problema de saúde? Qual? Você o relaciona ao seu trabalho?" e "Recebe apoio de amigos e familiares para motivação no trabalho?”.

Para validar o instrumento foi realizado na primeira semana de dezembro de 2014 um pré-teste com cinco profissionais que responderam a entrevista. Os resultados indicaram que o instrumento proposto era eficaz para atingir os objetivos deste estudo.

A entrevista foi aplicada pelos pesquisadores nas residências dos profissionais que informantes na pesquisa. As entrevistas aconteceram entre março a abril de 2015 e foram gravadas em áudio mediante autorização do informante.

Os dados levantados foram transcritos na íntegra e organizados por meio de categorização dos materiais e realizada análise do conteúdo de Bardin (1977). Quanto à identificação do informante na apresentação dos resultados opotou-se pelo uso de pseudônimos.

O Projeto de pesquisa deste estudo foi analisado pelo Comitê de Ética em Pesquisa da Universidade Presidente Antônio Carlos e aprovado pelo Parecer número 1.335.789.

\section{RESULTADOS E DISCUSSÃO}

\section{Caracterização da amostra}

Em relação ao sexo dos profissionais, oito eram mulheres e quatro homens, com idade variando entre 20 e 50 anos. No que diz respeito à escolaridade, sete possuiam o ensino superior completo, três o ensino médio completo, um tinha formação técnica, um ensino médio incompleto e um o ensino superior incompleto.

Quanto às relações civis, nove são casados, dois vivem em união estável e um é separado. Desses, dez têm filhos e dois não possuem. Em relação a com quem o profissional reside, nove moram com cônjuge, dois moram com cônjuge e filhos e um mora com outras pessoas. Em relação à renda, três ganham até um salário mínimo, três entre um e dois, três entre dois e três e outros três acima três salários mínimos.

\section{Satisfação e sofrimento no trabalho}

Quando questionados a respeito do trabalho causar prazer, observou-se que a maioria dos profissionais encontra prazer no trabalho realizado por ajudar o próximo, contribuir para melhoria na qualidade de vida da população ao levar informações, alívio das dores e ainda por fazer o ofício com amor, como se observa nas falas dos informantes abaixo:

"Sim, meu trabalho mim causa prazer quando acabo ou amenizo a dor do paciente." (Maria).

"Sim, no meu caso quando atendo uma pessoa necessitada, ou seja, de menor poder aquisitivo, entregando gratuitamente os medicamentos fornecidos pelo SUS." (Alana).

"Eu tenho prazer em trabalhar na minha área, amo o que faço, faço o que gosto, já é uma grande satisfação, dentro do meu trabalho até hoje não considero que tive alguma insatisfação com meu trabalho." (João).

Segundo Ferreira, Kusma e Ditteric (2009) o trabalho é o interesse central para a sociedade, desse modo, passa a produzir o prazer, a saborosa grandeza da vida, pois é por meio dele que o ser humano se engrandece e que as pessoas podem conquistar, desenvolver e se expressar.

O prazer no trabalho em saúde se dá na construção da realização e na possibilidade de construir um cuidado individualizado, que fortalece a identidade como trabalhador que tem liberdade para rearranjar o seu modo opera- 
tório de trabalhar, permitindo encontrar atividades e atitudes capazes de lhe fornecer prazer (Glanzner, Olschowsky e Kantoski, 2011).

$\mathrm{O}$ valor do trabalho na vida das pessoas e as transformações que ele é capaz de trazer são elementos que merecem especial atenção, assim é necessário intensificar as pesquisas relacionadas à dinâmica de prazer-sofrimento nas organizações (Meyer e Guimarães, 2013).

Questionados a respeito do sofrimento/ insatisfação com o trabalho, observou-se que diversas situações causam insatisfação ou sofrimento no trabalho, como falta de reconhecimento em relação aos esforços realizados na execução do trabalho, indiferença no relacionamento interpessoal entre os profissionais, falta de coleguismo, seja por parte dos profissionais como do paciente, como mostra os discursos abaixo:

"Meu trabalho me causa sofrimento, quando, por exemplo, não reconhece o valor do meu trabalho, o esforço que faço para estar ali atendendo o paciente." (Antônio).

"[...] quando sou tratada com indiferença, quando sou mal recebida, e meu trabalho não é valorizado, é horrível também ser chamada atenção na frente dos outros." (Carlos).

"Causa sim, quando você faz tudo para um paciente, no final você vê que ele não reconhece o trabalho que você fez com tanto amor e carinho." (Iara).

Para Glanzner, Olschowsky e Kantoski (2011) o trabalho em saúde nas Unidades de Saúde da Família é uma prática coletiva que tem como finalidade a promoção da saúde das pessoas, suas famílias e comunidade. É condicionado pelas relações entre os profissionais nos serviços de saúde e sociedade, sendo permeado por ações técnicas e interpessoais. Assim, o trabalho não é por si só, fator de adoecimento, mas determinadas condições de trabalho e seus contextos podem causar prazer e/ou desgaste no trabalhador, o que interfere diretamente na qualidade de suas intervenções. O trabalhador, quando satisfeito, sente-se reconhecido e, como consequência, executa seu trabalho com prazer, repercutindo positivamente nas atividades que realiza, quando em sofrimento, pode ter dificuldade de realizar seu trabalho com qualidade, repercutindo de forma negativa no cuidado em saúde.

O trabalho ocupa um lugar de grande relevância no processo de viver humano, sendo assim é pertinente dar lugar à expressão da subjetividade dos trabalhadores e permitir a participação destes no planejamento e organização do trabalho. Essa participação pode aproximar os trabalhadores do conhecimento global do processo de trabalho evitando a alienação e o sofrimento e promovendo o prazer e o bem-estar na atividade laboral (Almeida e Pires, 2007).

Os eventos desencadeadores de satisfação são prazer pelo que fazem e disponibilidade de tempo para praticar atividade física, já os insatisfeitos relacionam essa situação a muitas dificuldades encontradas no trabalho e ao fato de não serem reconhecidos pelos esforços realizados, como se nota nas falas abaixo:

"Eu considero que meu trabalho me oferece uma boa qualidade de vida, pois este né, meu trabalho me traz prazer, pois é através dele que meus sonhos são alcançados, e assim posso desfrutar das coisas boas da minha vida com a minha família, e através do meu trabalho que tenho uma vida confortável." (Amanda).

"Possuo uma boa saúde, meu trabalho me 
possibilita ter tempo suficiente para desenvolver atividades físicas, quando necessário eu passo por umas avaliações médicas." (Adriana).

\section{"[...] ACS como eu sempre enfrenta muitas} dificuldades, e que dificulta uma boa qualidade de vida, sol muito quente diariamente, alimentação fora dos horários, mochila pesada para carregar, distância né, para chegar em algumas localidades para atender algumas famílias."(Laura).

"A insatisfação que é fruto da mal remuneração, da falta de incentivo, e em relação a educação continuada, poderia está tendo educação continuada para os funcionários."(Maria).

"Quanto a minha qualidade de vida no trabalho não estou muito satisfeita, eu busco mais valorização profissional, há 11 anos sou agente e durante este período nunca me conformei com o salário, a forma como nossos colegas são tratados com indiferença, na verdade reconheço meu valor e dos meus colegas e continuo na luta."(Carlos).

Em um estudo realizado com 12 enfermeiros do Hospital Universitário Lauro Wanderley no tocante a percepção da QVT, foi observado de forma positiva, por poderem articular o trabalho, à família, financeiro e lazer e de forma negativa, por estarem esses elementos em desequilíbrio devido às dificuldades financeiras (Araújo, Soares e Henriques, 2009). Todavia, o trabalhador se submete a uma realidade dolorosa, onde a perspectiva de mudanças são poucas, devido aos baixos salários, falta de valorização profissional e ascensão (Rocha, 2012).

O trabalho, enquanto atividade humana, não pode ser reduzido apenas a um processo alienado onde o trabalhador se limita a cumprir normas e prescrições. $\mathrm{O}$ trabalho compreende a

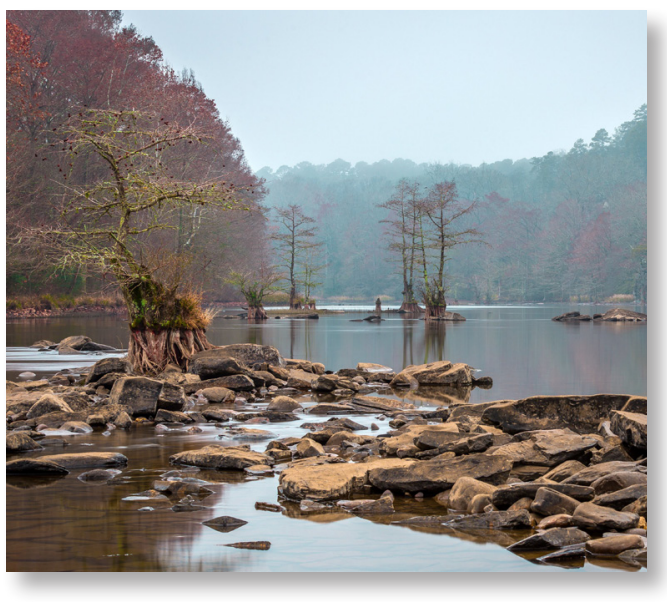

subjetividade de cada sujeito e pode ser fonte de sofrimento e de fadiga para uns e de prazer para outros. Falam ainda que o trabalho dos profissionais de saúde em unidades, não envolve apenas sofrimento, mas também a possibilidade de aliviar a dor e o sofrimento dos usuários e a probabilidade de salvar vidas humanas, fazendo com que possa ser fontes de conforto e satisfação que contribuem para o equilíbrio psíquico dos trabalhadores (Almeida e Pires, 2007).

Quando questionados se possuem algum problema de saúde, notou-se que alguns não possuem nenhum problema de saúde, enquanto outros possuem sintomas, como dores lombares, que pode está relacionada com o peso que carrega e posturas inadequadas na execução das tarefas. A presença deste sintoma pode interferir na percepção de satisfação com o trabalho e na QVT.

"[...] sinto muitas dores, né, na coluna lombar e cervical, tem relação sim com o trabalho por conta da mochila, né, que carrego e por andar muito." (Laura).

"[...] tenho desvio na coluna, o constante uso da bolsa de trabalho com materiais como balança, caderno, outros materiais essenciais agravam o problema, o ideal seria a mochila que distribui 
o peso igual, pois assim diminuiria um pouco as crises de dores." (Felipe).

Conforme Castilho (2010) as doenças de trabalho ou doenças ocupacionais acometem os trabalhadores de forma insidiosa e trazem consequências na Qualidade de Vida destes profissionais que pode ou não permanecer ao longo da sua vida.

A incidência de doenças ocupacionais vem crescendo muito e atingindo os mais diversos tipos de trabalhadores, gerando a necessidade de adaptações no ambiente de trabalho, entre elas as ergonômicas, como uma proposta educativa e preventiva das doenças ocupacionais (Sumariva e Ouriques, 2010).

Em relação ao apoio de amigos e familiares para se manterem motivados com o trabalho, nas respostas a este questionamento, verificou-se que todos os profissionais recebem apoio dos amigos e familiares, e tem essas pessoas como fonte de inspiração e motivação para trabalharem, conforme mostra os discursos abaixo:

"Sim, e como né, esse apoio é importante, pois se não fosse por isso às vezes agente até acabava desistindo de trabalhar." (Flávia).

"Sim, desde o primeiro dia de trabalho tive apoio da minha família, e da maioria dos meus amigos." (Alana).

"[...] tenho o apoio da minha família, em especial do meu esposo e a minha mãe, se não fosse eles eu não poderia vir até Serranópolis, ta trabalhando, porque tenho duas filhas, e com esse apoio, né, de estar me motivando vindo até aqui, se não, não conseguiria trabalhar aqui." (João).

"Com certeza, mais a minha maior motivação de continuar neste trabalho é o fato de gostar da profissão que visa qualidade de vida para a população e é também dele que tiro o sustento meu e da minha filha." (Ana).

De acordo Gessner et al. (2013) o apoio da família é muito importante na concepção de Qualidade de Vida, uma família bem estruturada e organizada é um ponto de apoio e também de estímulo ao trabalhador.

Desse modo, o reconhecimento é visto como algo recompensador em relação aos fatores geradores de sofrimento presentes no trabalho, que proporciona aos trabalhadores ânimo para seguirem trabalhando (Viero, 2014).

Cada trabalhador tem a sua própria necessidade, o que motiva um trabalhador pode não motivar o outro, e saber lidar com essas diferenças é um desafio das empresas para oferecer QVT a seus colaboradores. As empresas devem levar em consideração que nem todos estão no mesmo patamar, quando se diz respeito à motivação, mas que deve ficar atenta para a melhoria contínua na Qualidade de Vida do trabalhador (Marson et al., 2011).

A motivação do colaborador com seu trabalho, estão diretamente atreladas a fatores como salário, benefícios e remuneração, condições físicas e psicológicas do trabalho e também, a um ambiente de trabalho seguro (Alves, 2011).

No entanto, a motivação é algo que necessita estar continuamente sendo estimulada numa organização, de modo que o colaborador possa aplicar e desenvolver todo seu potencial dentro do seu trabalho e fora dele (Carvalho et al., 2013).

\section{CONSIDERAÇÕES FINAIS}

Quanto a percepção dos profissionais da saúde sobre sua QVT e vivências de prazer e sofrimento no trabalho, observou-se que o que traz prazer a estes profissionais é o ato de 
poder ajudar o próximo, dando-o alívio nos momentos de dores, informações, podendo contribuir com a Qualidade de Vida da população, ressaltam também que o sofrimento vem da insatisfação com a má remuneração, da falta de reconhecimento e desvalorização do trabalho executado, podendo assim acarretar danos tanto na saúde física como na saúde mental dos mesmos.

Neste sentido é preciso que estes profissionais tenham seu trabalho reconhecido, uma maior valorização quanto a função desempenhada, para que as vivências de sofrimento em torno do seu trabalho possam ser amenizadas. Diante deste contexto, cabe aos gestores deste serviço intervir no processo de trabalho dando-os melhores oportunidades para que possa haver maior desenvolvimento pessoal e profissional.

Espera-se que este estudo contribua para o meio acadêmico, forneça subsídios para futuras discussões e adequações dos serviços em saúde e contribua de forma significativa para trazer novos aprendizados para os trabalhadores da saúde.

\section{REFERÊNCIAS}

- Almeida, P.J dos S., Pires, D.E de. (2007). O trabalho em emergência: entre o prazer e o sofrimento, Revista Eletrônica de enfermagem, 9(3): 617-629, 2007. Recuperado de https://www.fen.u fg.br/fen_revista/v9/n3/pdf/v9n3a05. pdf.

- Alves, E.F. (2011). Programas e ações em qualidade de vida no trabalho. Revista Interfacehs, 6(1), 60-78.

- Andrade, R.M. (2012). Qualidade de Vida no Trabalho dos Colaboradores da Empresa Farben S/A Indústria Química. 52f. Monografia (Especialista em Gestão Empresarial) Criciúma: UNESC.

- Araújo, G.A., Soares, M.J.G.O., Henriques, M.E. de M. (2009). Qualidade de vida: percepção de enfermeiros numa abordagem qualitativa, Revista Eletrônica de
Enfermagem, 11(3): 635-641. [acesso: 21 jun. 2015]. Disponível em: https://www.fen.ufg.br/fen_rev ista/v11/ n3/pdf/v11n3a22.pdf.

- Carvalho, J.F. de, Martins, E.P.T., Lúcio, L., Papandréa, P.J. (2013). Qualidade de vida no trabalho e fatores motivacionais dos colaboradores nas organizações. Educação em foco, 7(1): 21-31.

- Castilho, C.R.N. (2010). A relação ao processo do processo de Enfermagem com o adoecimento desses profissionais: uma pesquisa bibliográfica. 40f. Monografia (Especialização em saúde pública) Faculdade de Medicina, UFRGS, Porto Alegre.

- Faria, H.P de. (2009). Processo de trabalho em saúde. $2^{\circ}$ ed. Belo Horizonte: Coopmed, 72p.

- Ferreira, C.G., Kusma, S.Z., Ditteric, H.R.G. (2009). Qualidade de vida e o trabalho sob a ótica da equipe de enfermagem em um serviço de urgência e emergência. Revista Gestão \& Saúde, Curitiba, 1(2): 17-25.

- Ferreira, T.K.M., Todescat, M., Weinzierl, G. (2012). Qualidade de vida no trabalho: um desafio a ser perseguido. Congresso virtual brasileiro de administração, p. 1-17. [acesso: 14 out. 2015]. Disponível em: http:// www.convibra.com.br/upload/paper/adm/adm_1355. pdf.

- Ferro, F.F. (2012). Instrumento para medir a qualidade de vida no trabalho e a ESF: uma revisão de literatura. 2012. 92f. Monografia (Especialização em Atenção Básica em Saúde da Família), UFMG, Brumadinho, Minas Gerais.

- Glanzner, C.H., Olschowsky, A., Kantoski, L.P. (2011). O Trabalho Como fonte de prazer: Avaliação da Equipe de um Centro de Atenção Psicossocial. Rev. Esc. enferm. USP, 45(3): 716-721.

- Gessner, C.L.S., Grillo, L.P., Sandri, J.V. de A., Próspero, E.N.S., Mariath, A.B. (2013). Qualidade de vida de trabalhadores de equipes de saúde da família no sul do Brasil, Rev. Bras. Pesq. Saúde, Vitória, 15(3): 30-37, jul./ set.

- Marson, L.S.C., Rodrigues, M.V.R., \& Calderón, P.A.L., Santos, I.C. dos. (2011). As relações entre motivação e qualidade de vida no trabalho: um estudo com técnicos administrativos de uma universidade pública do estado do Rio de Janeiro. In: Congresso Nacional de excelência 
em gestão (pp. 1-20). Rio de Janeiro.

- Meyer, A.M., Guimarães, L. de V.M. (2013). Encontro de gestão de pessoas e relações de trabalho. Brasília : DF, "Mais prazer ou mais sofrimento"? Um estudo com trabalhadores de agência bancária, Brasília: ANPARD.

- Paula, P., de, Stefano, S.R., Andrade, S.M. de, \& Zampier, M.A. (2011). Clima e cultura organizacional em uma organização pública. Gestão \&Regionalidade, 27(81): 5973.

- Roble, G.L.E. (2012). Qualidade de vida no trabalho: um estudo em empresas que publicam balanço GRI. 2012, 118f. Dissertação (Mestre em Administração). Sao Paulo: Universidade Católica de São Paulo.

- Rocha, A.M. (2012). Qualidade de vida no trabalho
(QVT): Um estudo na loja arco-íris na cidade de PicosPI, 67 f. Monografia (Bacharel em administração) Picos, Piauí:UFPI

- Sumariva, A., \& Ouriques, M.A. (2010). Qualidade de vida ocupacional dos profissionais de educação física que atuam nas academias de Blumenau SC nas modalidades de musculação e ginástica. 63 f. Monografia (Graduação em Educação Física) -Centro de Ciências da Saúde. Blumenau: Universidade Regional de Blumenau.

- Viero, V. (2014). Prazer e sofrimento dos trabalhadores de enfermagem em oncologia pediátrica, $187 \mathrm{f}$. Dissertação (Mestrado em Cuidado, Educação e Trabalho em Enfermagem). Rio Grande do Sul: Universidade Federal de Santa Maria.i

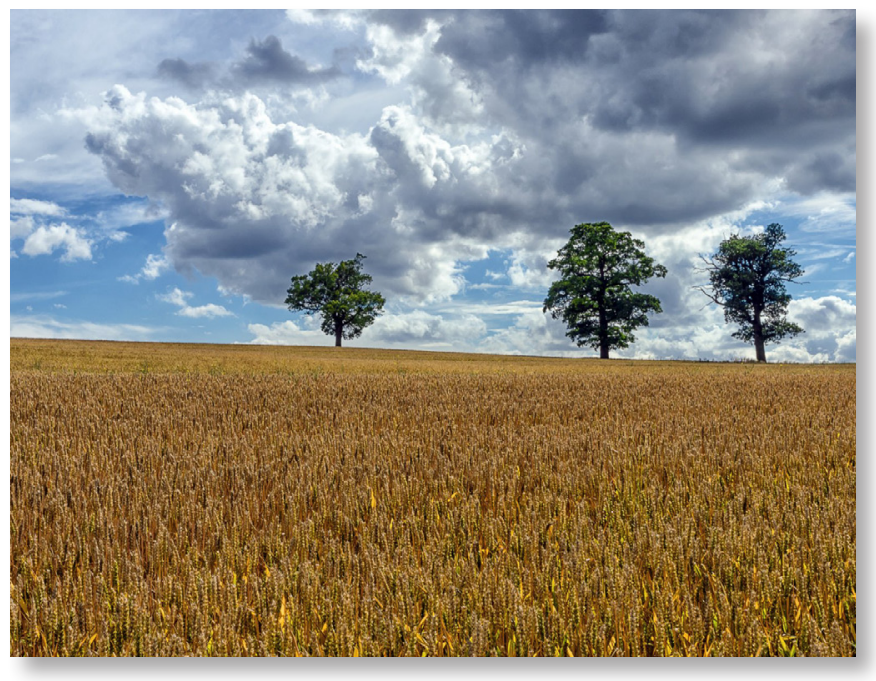

